\title{
Promoting computational thinking of both sciences- and humanities-oriented students: an instructional and motivational design perspective
}

\section{Zoltan Katai $^{1}$}

Published online: 3 April 2020

(C) The Author(s) 2020

\begin{abstract}
We proposed to investigate whether properly calibrated e-learning environments can efficiently promote computational thinking of both sciences- and humanities-oriented people. We invited two groups of students (sciences- vs. humanities-oriented members) to participate in a six-stage learning session: to watch a folk-dance illustration (s1) and an animation (s2) of the bubble-sort algorithm; to reconstruct the algorithm on the same input (s3); to orchestrate the algorithm on a random input stored in a white(s4)/black(s5) array (visible/invisible sequence) and to watch a parallel simulation of several sorting algorithms as they work side-by-side on different color-scale bars (s6). To assess the current motivation of students we created nine specific questionnaires (Q1-9). The experiment we conducted included the following task sequence: Q1-2, s1, Q3, s2, Q4, s3, Q5, s4, Q6, s5, Q7, s6, Q8-9. We focused on assessing the motivational contributions of the generated (situational factors) emotions, challenge and active involvement during the e-learning experience. Research results revealed that there are no unbridgeable differences in the way these two groups relate to e-learning processes that aim to promote computational thinking. Although sciences-oriented students' motivational-scores were consistently superior to their humanities-oriented colleagues, there was strong correlation between them; furthermore, differences diminished as both groups advanced with their learning tasks.
\end{abstract}

Keywords Computational thinking · Motivation · Learning · Instruction · Computer science education $\cdot$ Algorithms

\section{Introduction}

Hardly has any technology been as ubiquitous in human history as computer science is today. Therefore, a major responsibility of modern educational systems is to prepare all members of society for the challenges involved with the increasing digitalization of our everyday lives and to meet the demands of the one of the most fast-expanding job markets:

Zoltan Katai

katai_zoltan@ms.sapientia.ro

1 Sapientia Hungarian University of Transylvania, Corunca, 1C, Târgu-Mureş, Romania 
computing (Grover and Pea 2013).The creation of a genuine educational program which ensures a proper initiation in computational thinking (CT) is a major endeavor. As in most countries there is already a severe computational literacy gap among the different segments of society, this educational program must be all inclusive and must address all irrespective of age, gender, race, culture, orientation or disability.

Accordingly, one of the most serious challenges faced by such an initiative is that of dealing effectively with diversity. In this study we have focused on one specific facet of diversity: sciences- vs. humanities-oriented people. After Snow (1959) had introduced the term of "two cultures", the concept of sciences/humanities-oriented learner arose and it was suggested that these two categories of people are characterized by different cognitive styles, often described as the individual difference in the way people acquire and process information (Witkin et al. 1977; Achter et al. 1999; Billington et al. 2007). On the other hand, taking learner diversity into account is a very complex task. Since motivation plays a crucial role in learning and constitutes a key element in all the approaches to active learning (Valle et al. 2011), the impact of diversity on learners' motivation is a critically important aspect of the addressed educational issue.

The question we have proposed to analyze as follows: Is it possible to create unified learning environments that promote CT for all? In a previous work (Katai 2015) we presented research results showing that properly calibrated learning environments have the potential to effectively promote the computational thinking of both sciences-oriented and humanities-oriented students. In this paper we analyze the specific motivational challenges that instructional designers could face in developing learning environments which bridge the diversity gap and targets both learning communities.

\section{Promoting algorithmic/computational thinking}

The term CT was originally introduced by Wing (2006). In this paper we will use a revised definition of the term: the thought process involved in formulating problems so that "their solutions can be represented as computational steps and algorithms" (Aho 2012). Accordingly, a strongly related concept to CT is algorithmic thinking: a set of abilities that are connected to understanding, processing and constructing algorithms (Futschek 2006). Denning (2009) also emphasizes that algorithms are central to CT. More recently, he underlines that algorithms must control some computational model, and step sequences that require human judgment should not be considered algorithms in the context of CT (Denning 2017). As we described in (Katai 2015) we have proposed to enhance CT by inviting students on a "delicious algorithmics tasting tour" (in the mini-world of sorting algorithms: bubble-sort, insertion-sort, selection-sort, shell-sort, quick-sort and merge-sort) based on multiple algorithm visualizations (AV). The learning environment we created facilitates the simulation-based study of the selected algorithms in a relevant, accessible and engaging way (supporting users in assimilating the algorithm processing role of computers). It can be set up to generate the following leaning experience:

(1) the algorithm is visualized by a videotaped "sequence of folk dancers" (AlgoRythmics 2019) wearing the numbers to be sorted on their dresses;

(2) the algorithm is animated on a white-box array (the number-sequence is visible) (Katai, 2014), followed by 
(i) student reconstructed

(ii) and orchestrated animations;

(3) students are invited to orchestrate the studied sorting algorithm on a black-box array (the number-sequence is hidden; the user is informed only about the results of the comparison operations) (Katai 2014);

(4) the six algorithms are visualized as they work side-by-side on six different color-scale bars.

Of course, such a learning experience is only a first step in developing students' CT. Definitions of CT emphasize that cultivating this skill implies more than assimilating ready-made procedures. It implies devising procedures. For example, Selby and Woollard (2013), after investigating several definitions, conclude that CT "is a focused approach to problem solving, incorporating thought processes that utilize abstraction, decomposition, algorithmic design, evaluation, and generalizations". Studying basic computer algorithms in the AlgoRythmics environment could be a good starting point in this sense, especially if we choose to improve students' CT by computing education (Guzdial 2008; Tedre and Denning 2016).

Constructivist learning theory provided the main theoretical framework for this study. Constructivist learning environments are student-centered, engaging and reflective, and make it possible for students to learn from their experiences (Jonassen et al. 1999). According to Wang (2009) such a learning environment assumes attentive and thoughtful design. We purposefully focused on implementing the following previous research results regarding effective CT promoter learning environments.

- Why visually illustrated algorithms? Since computer algorithms are inherently abstract dynamic processes, AV has become the common approach to make them more tangible. We chose to visually illustrate how algorithms work by videotaped dance-performances and computer-based animations (Shaffer et al. 2010). The meta-analysis performed by Hoffler and Leutner (2007) emphasizes the educational superiority of representational animations, compared to static pictures, especially when procedural-motor knowledge has to be assimilated.

- Why sequenced multiple representation? The basic idea of using sequenced multiple AVs is that users can benefit from the properties of each representation (Meij and Jong 2006). Two key attributes of multiple representations are complementarity and redundancy. Redundancy is essential to make learners able to relate to different representations. Complementary attributes can be used to implement the principle of progression with respect to the informational content, complexity, level of abstractness and the control the learner has in the algorithm animation process. We use four different representations of the number sequence to be sorted: embodied by a dancer-sequence, stored in a white-box array, stored in a black-box array and illustrated as a color-scale bar.

- Why interactive learning environment? The (Hundhausen et al. 2002) meta-study stresses the decisive role interactivity has in effective AVs. This study concludes that AV's promote effective learning when users are engaged actively in the visualization process (instead of passively viewing it). In other contexts the same phenomenon was observed (for example: Mork 2011). To implement this principle of "genuine active involvement" the software we designed invites users to orchestrate the studied algorithms (Mayer and Chandler 2001). 
- Why applying selective hiding? According to Katai (2014), applying hiding may support human viewers in assimilating the algorithm processing role of blind-computers due to its higher epistemic fidelity. During the black-box based algorithm orchestration processes, since the stored number are invisible, users are forced (as computers too) to perform explicitly (not only implicitly in their minds) the comparison operations in order to realize whether the corresponding elements have or do not have to be swapped.

- Why pattern recognition oriented strategy? Since algorithms are in fact generalized patterns intended to solve problems, CT assumes pattern recognition and generalization skills (Wu and Richards 2011). Humans are unbeatable pattern recognizers in most instances (Jain et al. 2000). Obviously, learning from examples assumes carefully selected examples (Jain and Duin 2004). The interactive learning environment we created implements the following pattern recognition-oriented CT promoter method: (1) students are presented with illustrations of the algorithm on carefully selected sample inputs and (2) students are invited to enhance and refine their understanding by orchestrating the algorithm on random inputs.

\section{The motivational perspective}

The impact of diversity on education has been researched from several perspectives. One of them is the motivational perspective. On the other hand in motivational research little attention has been paid to study the impact of orientation (sciences/humanities) on motivation. Additionally, the specific motivational challenges of developing students' CT were also poorly researched. In this paper we focus on the instructional and motivational design aspects of the learning environment the software-tool we developed generates. We tried to identify motivational principles that could have key roles in arousing and sustaining students' (sciences/humanities-orientated) motivation during e-learning processes that aim to promote CT.

Motivation helps people to pursue goal-directed behaviors and activities, like learning. It serves to energize students, providing intensity and direction. Motivation theorists distinguish between intrinsic motivation (referring to the internal drive; doing something because it is inherently interesting or enjoyable) and extrinsic motivation (arising from factors outside the individual; doing something because it leads to a separable outcome) (Deci and Ryan 1985). Although developing successful motivational strategies assumes an optimal combination of these two types of motivational resource (Omrod 2002), the outstanding role that intrinsic motivation has in promoting high-quality learning is unquestionable (Fair and Silvestri 1992; Martens et al. 2004). Accordingly, motivational design is a systematic process to make instruction more intrinsically interesting (Keller 1983).

According to motivation theorists, learning environments that engage students in the learning process yield stronger intrinsic motivation (Lepper et al. 2005; Robertson and Howells 2008). Research in this field has revealed some major factors supporting students' motivation. Three of them are positive emotions, moderate-progressive challenge and active involvement, which may have a distinguished role in computer-mediated environments (Finneran and Zhang 2005). Research results in game-based learning also inspired us in selecting these motivational behaviors. For example Hamari et al. (2016) analyzed the impact of challenge, engagement, and immersion on learning in game-based learning environments. The sense of immersion is directly related to the emotional composition of the learning experience (Fassbender et al. 2012). Studies in 
serious games also emphasize the importance of player's emotion by describing it as the main player characteristic considered to be important for learning processes and performance (Schrader et al. 2017).

Recent evidence show that emotions are not only outcomes of motivated behavior, but they also influence the cognitive processes associated with motivation (Triberti et al. 2017; Um et al. 2007). For example, emotion often underlies curiosity, which is commonly regarded as a prime promoter of intrinsic motivation (Malone and Lepper 1987; Litman 2005). Research on challenge as a motivator shows that promoting challenge-skills balance is optimally motivating (Nakamura and Csikszentmihalyi 2002; Turner and Meyer 2004; Ott and Tavela 2010). Relevant active involvement could be decisive in promoting intrinsic motivation, since it may have a crucial influence on sustaining students' engagement during the learning process until the knowledge construction has been completed (Lepper and Malone 1987; Garris et al. 2002).

Inviting learners to participate in sequenced learning units generates additional motivational challenges. The output-emotions of the current phase of a learning session are inputemotions for the next phase (Wlodkowski 1985). A relevant active role in a challenging learning session contributes to a sense of achievement. In addition, the way students think about the next learning unit generates corresponding emotions. Perceiving inappropriate challenge may result in anxiety or boredom (Csikszentmihalyi 1990). On the other hand, the probability of success can promote exciting expectations. Teachers may have a key role in promoting the above "learning ingredients" (Christophel 1990), but technology has also its own strengths (Barger and Byrd 2011).

The (Rovai et al. 2007) study concludes that online e-learning may foster stronger intrinsic motivation than traditional classroom learning. On the other hand, Otta and Tavela (2010) emphasize that "new millennium learners" (Pedró 2006) are not indifferent to the quality of the e-learning experience. Most frequently recalled deficiencies of e-learning materials are: lack of edge and emotion, absence of a great beginning and ending, too much sameness, etc. On the other hand, if e-learning materials are interesting only-for example-because they are novel, then they may lose their appeal as learners become accustomed to them. It is clear that simply adding some multimedia elements is not enough to significantly increase and sustain intrinsic motivation (Hamid 2001; Clark and Mayer 2002; Keller and Suzuki 2004; Martens et al. 2004). Therefore, we have proposed to implement the following motivational strategy:

- Arousing motivation During the "dance-performance phase" the focus is on arousing curiosity by combining science with art and modern with traditional. In order to test if the created "algorithmic dances" have the potential to provide novelty, incongruity and surprise (Keller 1983; Berlyne 1960) we posted them on the YouTube website. Users' reactions confirmed our expectations. Artistic elements play a key role in attracting humanities-oriented people. The presence of culture may also promote emotional motivation.

- Sustaining motivation The role of the "animation phase" is to help students to focus on the key elements of the algorithm (Mayer 2003; Kalyuga et al. 1999) and to prepare them for the "doing phases". During the "doing phases" (reconstruction, "white-box orchestration", "black-box orchestration") of the e-learning session, students are invited to actively participate in the animations (Mayer and Chandler 2001) according to the principle of moderate-progressive challenge. According to constructivist learning theory, learning from their experiences and applying the knowledge they have just gained may result in more effective learning (Jonassen et al. 1999). 
- In the conclusion part the "sorting-movie" that we created (displaying the parallel sorting of the six color-scales) aims to arouse aesthetic emotions and to provide a global view of the studied topic. Aesthetic emotions can contribute to a great ending to the learning experience (Parrish 2009; Riaz et al. 2011).

As we mentioned above, two other important motivational factors related to the moderate challenge are anxiety (fear of failure) and probability of success. In line with Keller's ARCS (attention, relevance, confidence, and satisfaction) model of motivation (Keller 1987), in order to guarantee that students can accomplish the tasks (and to reduce anxiety), we provided them with help-buttons that indicate the next operation to be performed. Moreover, each animation task can be repeated (for different randomly generated inputs) until it is solved correctly and without using the help buttons. This option aims to promote the desired sense of achievement.

\section{Method}

We designed an experiment to analyze the motivational impact of the e-learning environment we elaborated. The investigation involved 48 undergraduate students from an Eastern Europe university (Romania). The independent variable was students' orientation [25: (S) cience-students; 23: (H)umanities-students]. The percentages of females were 12\% (S-students) and $82 \%$ (H-students) which is characteristic in the case of these educational programs. H-students were IT users but strangers to computer programming (87\% of them had not attended any programming oriented courses during their high-school education; the rest had only some minimal Computer Science concepts included in their high school curriculum). We performed the experiment after the S-students had been initiated in programming. Both groups studied the selected sorting algorithm (optimized bubble-sort) by following the above presented six-stage learning session. To be able to measure students' performance results the software registered all the errors they made and their help requests.

Although there are many motivation questionnaires used in educational psychology we have proposed the development of a specific questionnaire-sequence for this study. Several studies (Blumenfeld 1992; Blumenfeld and Meece 1988; Lee and Anderson 1993; Lee and Brophy 1996; Weiner 1990) conclude that students may express different motivational traits when studying specific subject content areas. According to the classical model of motivational psychology, personal and situational factors influence the current motivation which in turn influences learning. Rheinberg et al. (2001) proposed a questionnaire with 18 items for assessing the current motivation of students working on a specific task. Researchers like Vollmeyer et al. (2000) and Friedl et al. (2006) used this instrument to investigate motivational characteristics of students learning in interactive multimedia environments. We adapted this method and worked out a set of nine specific questionnaires (Q1-9; see Appendix) to detect the level and type of students' motivation during the e-learning experience we designed.

The questionnaire items aimed to detect the way students think and what they are filling before and after the e-learning session (unit) and between the consecutive stages (subunits). While the questionnaire proposed by Rheinberg et al. (2001) is built around factors like probability of success, anxiety, interest, and challenge, we have focused on assessing the motivational contributions of the generated (situational factors) positive/negative emotions, challenge and active involvement during the e-learning experience. We expected to find significant differences between $\mathrm{H}$ - and S-students. 
We addressed the following research questions:

- What motivational principles could play a key role in arousing and sustaining students' motivation during e-learning processes that aim to promote CT?

- Are motivational differences (with respect to CT) between humanities- and sciencesoriented students unbridgeable?

- Can CT promoter learning environments (supporting students to assimilate and process computer algorithms) be calibrated in such a way to be motivating for all students?

Each questionnaire item included a statement and a response scale. We used a 7-point scale (1: Strongly Disagree,.., 7: Strongly Agree). We coded the items as follows. Letters E, C and I refer to Emotions, Challenge and Involvement. "E-items" aim to detect emotions resulting from three sources:

- How interesting the previous e-learning stage was and the next one seems to be.

- How challenging the previous e-learning stage was.

- How “exciting" student's involvement in the previous e-learning stage was.

"C-items" aim to detect the level of challenge the student anticipates in the next e-learning sub-unit. The "I-items" aim to detect the way the students think and what they are filling regarding their forecasted involvement in the next e-learning sub-unit.

\section{Procedure}

The experiment was conducted in computer labs where all students had individual access to the online e-learning tool. Before the e-learning session started, students had briefly been initiated in or reminded of concepts such as: why is important CT? What is an algorithm? Why could studying sorting algorithms be beneficial? What is a sorting algorithm? In addition, a brief overview of the six phase e-learning session was presented to both groups. After the above presented introduction (hearing phase) students were invited:

- (Q1) to answer 5 questions regarding algorithms and CT;

- (Q2) to answer 11 questions regarding the anticipated e-learning experience;

- s1: (seeing phase 1: arousing/stimulating motivation) to watch the danced algorithm; (surprising science-art, modern-traditional combinations) (Fig. 1)

- (Q3) to answer 9 questions regarding the "dance-stage" that had just finished and the "animation-stage" that was about to start;

- s2: (seeing phase 2: supporting abstracting) to watch the animation of the algorithm; (Fig. 2)

- (Q4) to answer 12 questions regarding the "animation-stage" that had just finished and the "reconstruction-stage" that was about to start;

- s3: (doing phase 1: active involvement, progressive challenge) to reconstruct the operation (compare, swap) sequence of the observed animation;

- (Q5) to answer 17 questions regarding the "reconstruction-stage" that had just finished and the "orchestration-stage" that was about to start; 


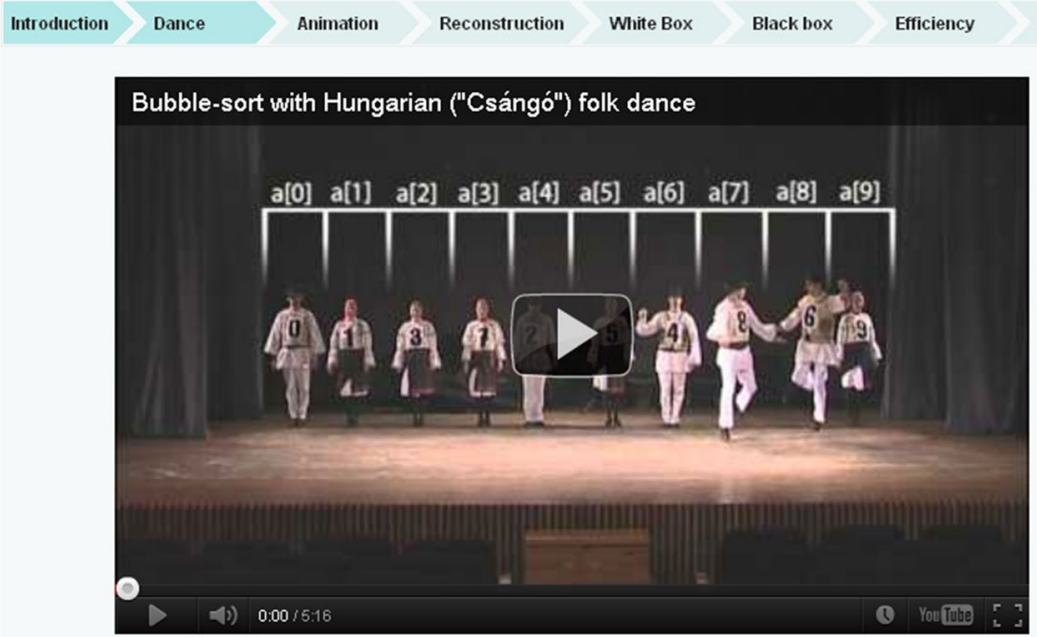

Go to the next stage

Fig. 1 Sorting-dance

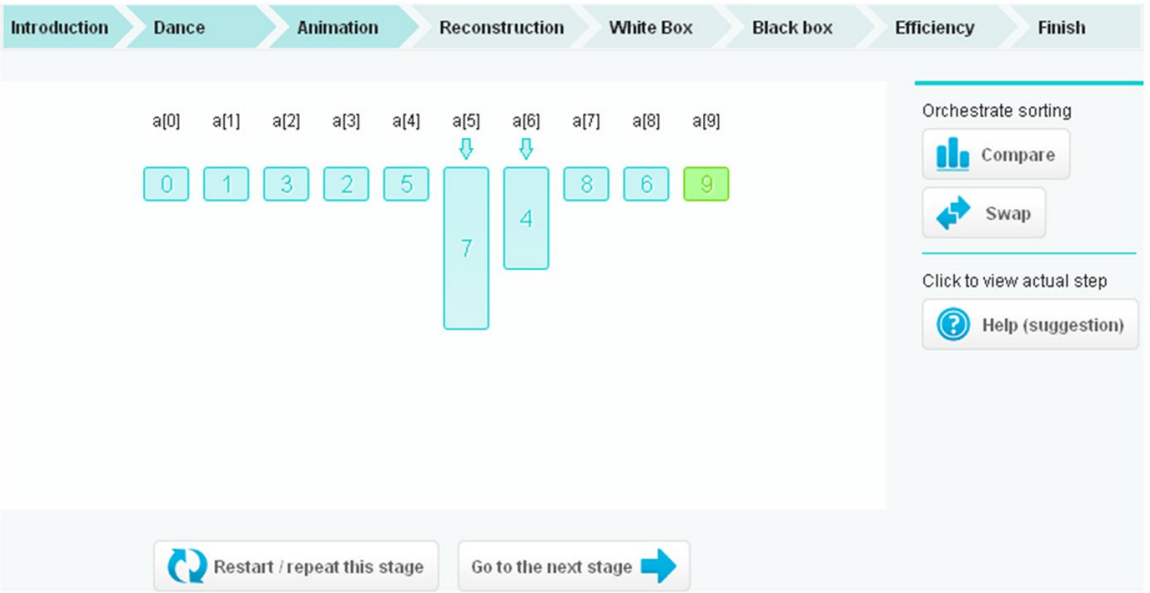

Fig. 2 Animated algorithm

- s4: (doing phase 2: active involvement, progressive challenge) to orchestrate the algorithm on a randomly generated sequence stored in a white-box array (the numbers being visible); (Fig. 3)

- (Q6) to answer 17 questions regarding the "orchestration-stage" ("white-box-stage") that had just finished and the "black-box-stage" that was about to start;

- s5: (doing phase 3: active involvement, progressive challenge) to orchestrate the algorithm on a randomly generated sequence stored in a black-box array (being informed about the results of the comparison operations); (Fig. 4) 


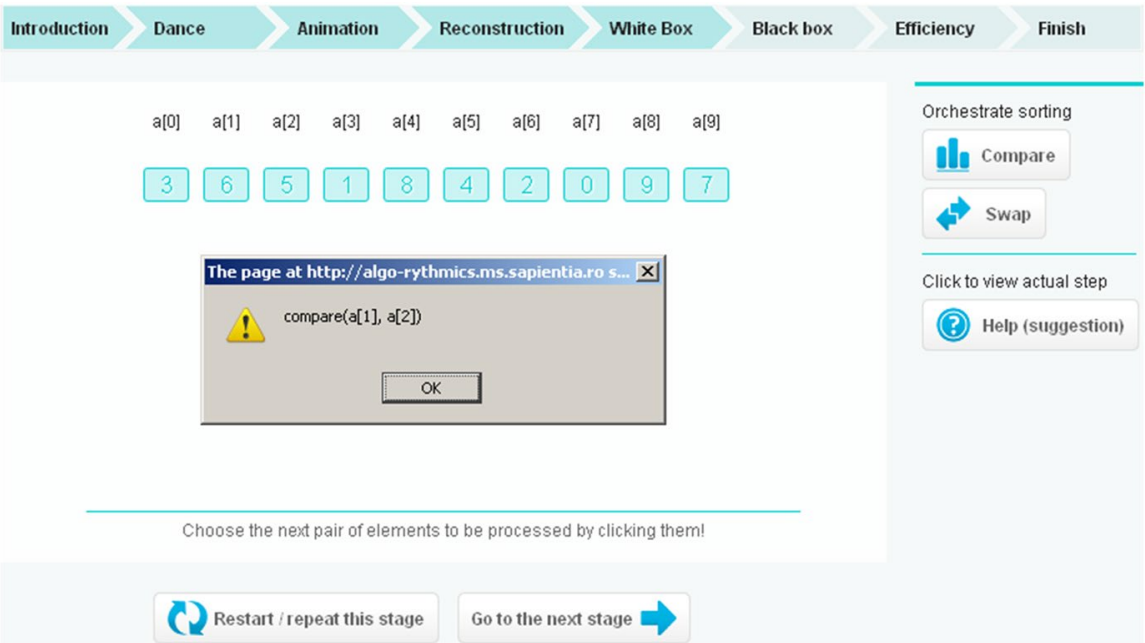

Fig. 3 White-box task (help request)

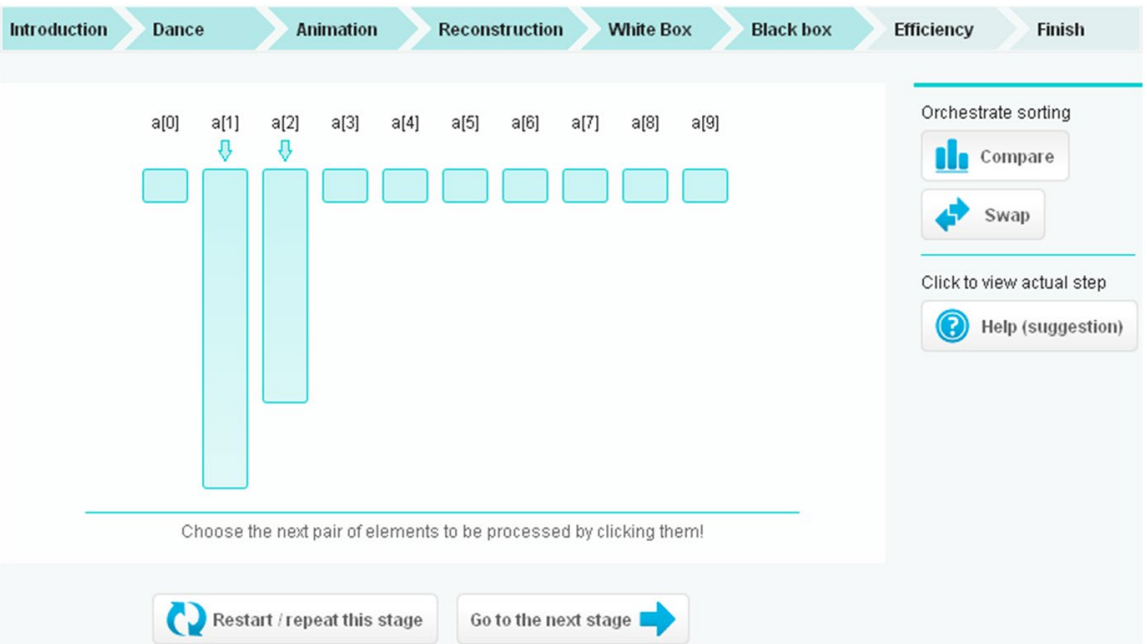

Fig. 4 Black-box task

- (Q7) to answer 13 questions regarding the "black-box-stage" that had just finished and the "parallel-simulation-stage" that was about to start;

- s6: (arousing aesthetic emotions) to watch a nice parallel simulation of the six sorting algorithm (different sorting algorithms are visualized as they are working side-by-side on different color-scale bars); (Fig. 5)

- (Q8) to answer 4 questions regarding the "parallel-simulation-stage" that had just finished;

- (Q9) to answer 9 questions regarding their global impressions on the e-learning session they had just finished. 


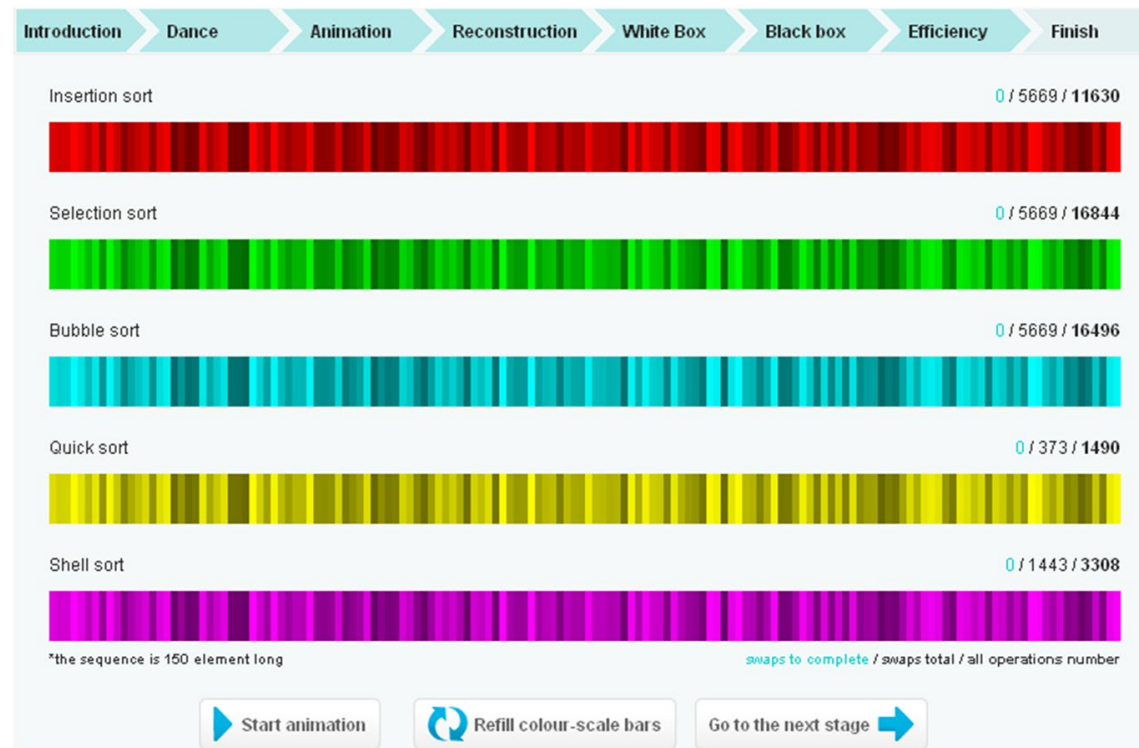

Fig. 5 Parallel simulation of the sorting algorithms

\section{Results}

Analyzing the on-line reports we concluded that $95.65 \%$ of the S-students (group-Sa) assimilated the studied algorithm. In the case of $\mathrm{H}$-students this percentage was $73.91 \%$ (group-Ha). These conclusions reflect students' performance during their black-box task. As reported in (Katai 2015) the differences between the corresponding numbers of errors diminished as both groups advanced with their e-learning tasks (Fig. 6). A similar phenomenon could be observed regarding help request numbers.

\section{Results regarding the motivational perspective}

A reliability analysis was carried out on the questionnaire items. Cronbach's alpha, the measure of internal consistency for Likert-type scales showed that the questionnaire

Fig. 6 Number of errors

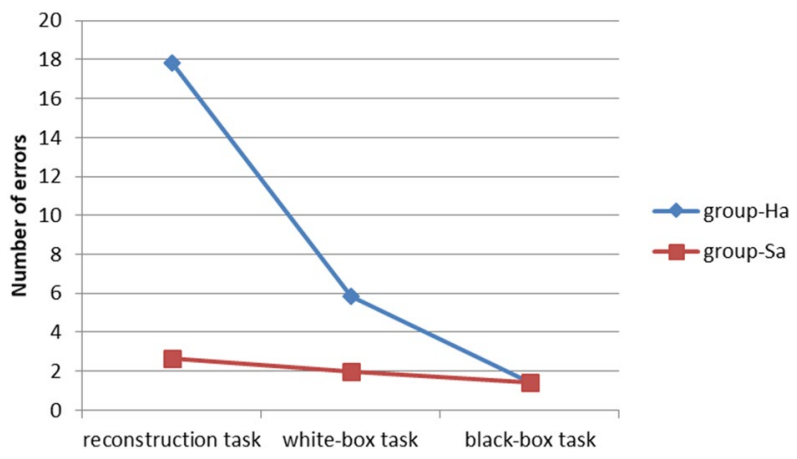


items as grouped in the analysis reached acceptable reliability (for Fig. 7, $\alpha=0.92$; for Fig. 8, $\alpha=0.84$; for Fig. 9, $\alpha=0.88$; for Fig. 10, $\alpha=0.79$; for Fig. 11, $\alpha=0.87$ ). In all cases, all items included in the analysis appeared to be worthy of retention, as the deletion of none of them would have resulted in an increase of the internal consistency of the measure. (In the followings notation $\mathrm{qx} / \mathrm{y}$ refers to item $\mathrm{y}$ of questionnaire $\mathrm{x}$; notation qa-b/y refers to item $\mathrm{y}$ of questionnaires a..b; notation qx/a-b refers to items a..b of questionnaire $\mathrm{x}$ ).

Generally speaking, both groups positively appreciated the e-learning experience. Figure 7 shows groups' appreciation-scores during the learning process: (q2/1) "I liked the idea behind this e-learning session"; (q3-8/1) "I liked this phase of the e-learning session"; (q9/1) "I liked this e-learning session". Groups' scores referring to the initial statement (q2/1) were: 5.35 points (group-Ha, $72.5 \%$ ) and 6.46 points (group-Sa, 91.33\%). We

Fig. 7 Appreciation-scores

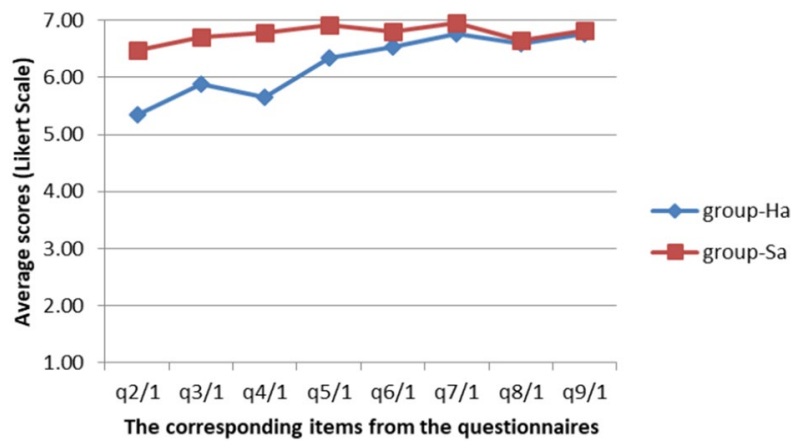

Fig. 8 Estimated understanding

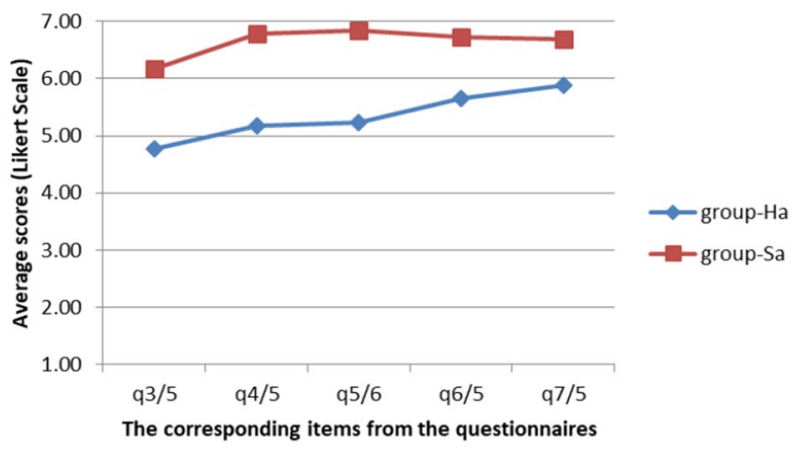

Fig. 9 Level of anxiety

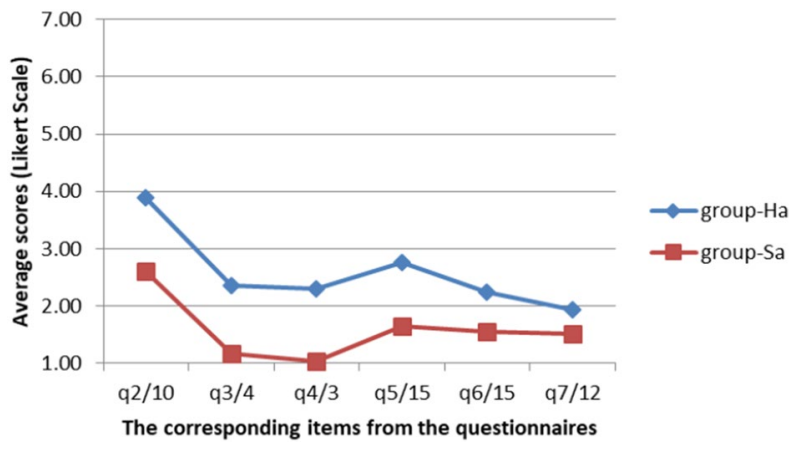




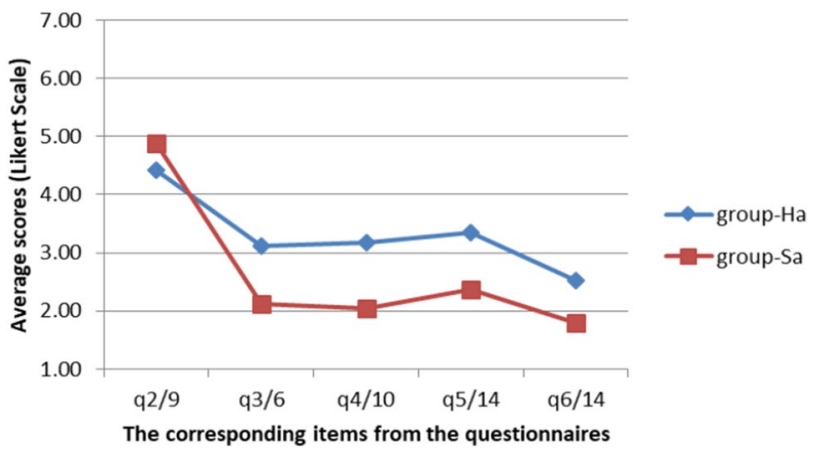

Fig. 10 Perceived challenge

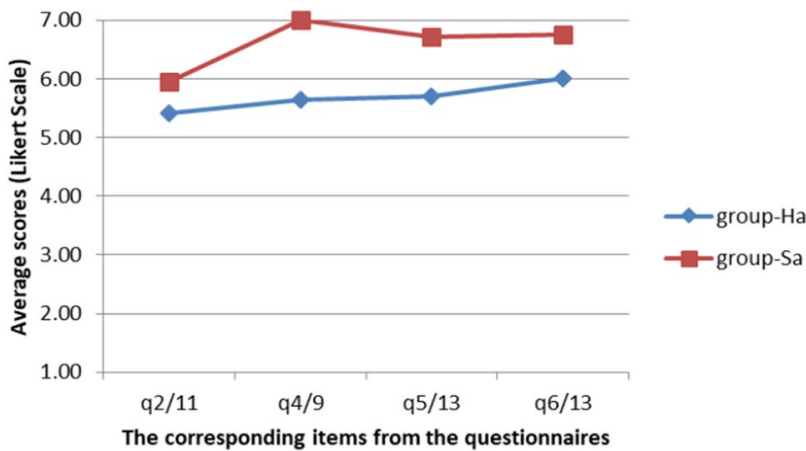

Fig. 11 Active involvement

managed to sustain and even gradually increase these initial levels of motivation. Groups' scores regarding the global impression statement (q9/1) were: 6.76 points (group-Ha, 96\%), 6.83 points (group-Sa, 97.17\%). To test if differences between groups (regarding the whole learning process) were significant we performed a MANOVA. The grouping variable was students' orientation. We chose as dependent variables students' scores referring to statements q2-9/1. Test results confirmed our expectation that $S$-students mostly appreciate this kind of learning experience $(\mathrm{p}=.0009)$.

Comparing (with paired samples t-test) the means of H-students' scores respects to statements q2-4/1 ("hearing and seeing phases": 5.63 points, $77.17 \%$ ) with the means referring to statements q5-7/1 (“doing phases": 6.55 points, $92.5 \%$ ) we detected a significant increase $(\mathrm{p}=.0000)$ in their appreciation level. This increase significantly diminished the size of the differences between groups. Interestingly, this increase took place in spite of the fact that students made quite a lot of errors during the "reconstruction task" (Fig. 6).

Regarding other global impression statements like "I liked this e-learning session because of its interestingness/challenge/interactivity" (q9/2-4) S-students' appreciations were superior to those of H-students', but no significant differences were detected. Additionally, both groups set up the following relations between the motivational contributions of the studied factors: "interestingness" <"challenge" (group-Ha, $\mathrm{p}=.0133$; group-Sa, $\mathrm{p}=.03$ ) and "challenge" < "interactivity" (group-Ha, $\mathrm{p}=.2313$; group-Sa, $\mathrm{p}=.003$ ) (we applied paired samples t-tests). Since the dance choreography illustration was the most 
distinctive part of the generated learning experience, we compared the two groups' appreciation scores regarding this component before (q2/2: "I consider that combining arts with sciences is an interesting idea") and after (q9/5: "I liked this e-learning session because of the dances") the learning session. While H-students reported approximately the same appreciation level at the end as at the beginning of the experiment (83\% vs. 77\%), S-students' appreciation increased significantly ( $87 \%$ vs. $97 \%$; paired samples t-test, $p=.04)$. In other words, while both groups indicated equally high scores in anticipation (group-Ha: $82 \%$, group-Sa: $87 \%$ ), the appreciation score reported after the learning session by groupSa was significantly higher than the group-Ha's score (group-Ha: 77\%, group-Sa: 97\%; two samples t-test, $\mathrm{p}=.0002$ ).

Comparing (MANOVA) groups' scores referring to statements "I caught the logic of the sorting strategy" (q3/5, q4/5) and "I reached this performance because I understood the strategy the algorithm applies" (q5/6, q6/5, q7/5) we found significant differences $(\mathrm{p}=.0014)$ in favor of S-students (Fig. 8). Examining the graphics separately we noticed the following:

- Group-Sa reported steep increases in their understanding after they had watched the dance-performance and the animation. Performance results more or less confirmed these estimates (Fig. 6). During the "doing phases" they adjusted their estimates to correspond better with their real level of understanding.

- In the case of group-Ha a gradual increase can be observed in students' auto-estimated levels of understanding. However, performance results did not confirm these scores (Fig. 6). During the reconstruction task H-students realized that they had not understood the algorithm adequately and after this phase they did not report further increases in their level of understanding. Group-Ha's estimates were (relatively) consistent with their performance results only after the white- and black-box tasks. Thanks to the "doing phases" of the learning process H-students' sensations that they caught the logic of the strategy were followed by real increases in their understanding.

Figure 9 shows groups' scores referring to statements "I am afraid / consider that what this e-learning session implies is beyond me" (q2/10, q5/15, q6/15, q7/12) and "I did not realize what was going on" (q3/4, q4/3). Both groups reported relatively lowlevel feelings of anxiety and a strong correlation can be observed between their responses $(r=0.86>0.70)$. Although H-students' scores were significantly superior to those of their S-colleagues' (MANOVA, $\mathrm{p}=.0056$ ), the size of the differences diminished as the two groups advanced during the learning process. These graphics also reveal that both groups overestimated their level of understanding after "seeing phases" and emphasize the outstanding importance of the "doing phases" in such learning topics. We also observed strong correlations between students responses to statements (q5/15, q6/15, q7/12) and the number of errors they made during the "doing phases" (group-Ha, $\mathrm{r}=0.99>0.87$; groupSa, $r=0.98>0.87$ ) (see Fig. 6).

After students had watched the danced algorithm both groups understood more clearly what a sorting strategy means. The moderate challenge students perceived starting from this point (Fig. 10; q3/6: "This e-learning session seems to be a challenging one", q4/10: "To reconstruct the same operation-sequence does not seem to be a complicate task", q5/14: "To orchestrate this strategy on random input sequences will be a challenging task", q6/14: "Since I caught the logic of the strategy no problem for me to orchestrate it on hidden sequences") explains their large global impression scores regarding the motivational contribution of the challenge-factor (q9/3). Although the challenge perceived by group-Ha 
was superior to group-Sa, the difference between them was not significant (MANOVA, $\mathrm{p}=.2)$. On the other hand there was a strong correlation $(\mathrm{r}=0.94>0.75)$ between groups' responses and the differences diminished towards the end of the learning session.

Figure 11 shows the scores the reported by the two groups on the subject of students' forecasted involvement in following learning-unit (q2/11, q4/9, q5/13, q6/13; "I appreciate that the software makes possible to do (reconstruct/orchestrate) ..."). Differences are significant (MANOVA, $\mathrm{p}=.0008$ ). After the "seeing phases" both groups were more motivated to be involved in the learning process than at the beginning of the session (group-Sa reported maximal score at this point). Considering the whole learning process, H-students' scores indicate a continuous increase.

\section{Discussion}

Research results presented in this paper provide new insights into the motivational behavior of sciences- and humanities-oriented learners within a CT promoter learning environment. One of the main conclusions of this research in that there are no unbridgeable differences between the ways $\mathrm{H}$ - and $\mathrm{S}$-students relate to CT promoter e-learning tools. We found strong correlations between both the performance-results and motivational-scores of the groups. Additionally, S-students' superiority over their H-colleagues (in both aspects) progressively and significantly diminished as the groups advanced with their e-learning tasks.

S-students' superiority with regard the majority of test items is a quite evident result and is in line with previous studies in the topic of cognitive style characterized by the psychological dimensions of empathizing and systemizing (Baron-Cohen 2003). Billington et al. (2007) studied the cognitive style of sciences- and humanities-oriented students. Their research evidence indicates a "systemizing > empathizing" profile for science students (as a group), and an "empathizing > systemizing" profile for humanities ones (as a group). Obviously, studying algorithms implies, first of all, systemizing which is defined by the authors of the aforementioned study as the drive and ability to analyze a system in terms of an INPUT_OPERATION_OUTPUT principle. The surprising finding of this research is the way that $\mathrm{H}$-students have caught up with their S-colleagues.

Sequenced multiple representation, besides its direct cognitive benefit (implementing the principle of gradual shift from concrete to abstract), allowed us to explore multiple motivational resources. Whilst students considered the dance-performance mainly to be interesting, they found the black-box task to be exciting (because of its challenge and interactive character). Whilst the dance-performance helped students to imagine what a sorting algorithms means, the black-box representation helped them to focus on the key elements of the strategy (on which sequence of element-pairs, what operations, compare or compare + swap, should be performed). For example, Katai $(2014,2015)$ reported that students sorting hidden sequences skipped significantly less frequently comparing operations than those working on visible sequence.

Another conclusion of this research is that-in CT promoter environments-the principles of "moderate-progressive challenge" and "genuine active involvement" are more effective motivational resources than interestingness. In addition, interestingly, S-students appreciated the dance choreography representation better than H-students.

Since the concept of moderate challenge implies a relatively large range of challenge, we were able to calibrate the learning environment such that it was appropriately challenging 
to both groups. To keep the challenge factor at an optimal level, the learning environment offers users the possibility of skipping or repeating certain units. Whilst H-students needed all three "doing phases", in the case of S-students the "reconstruction phase", or even the "white-box orchestration phases", could be skipped.

Experiment results emphasize the determinative role of the "genuine active involvement" in promoting CT. The "doing phases" of the learning process, besides unmasking false sensations of understanding (especially in the case of H-students) revealed students' misconceptions and helped them to really catch the logic of strategy. As a consequence students became more motivated to succeed.

These results harmonizes with the findings of game-based learning research which also emphasizes the importance of the challenge factor. A recent study performed by Hamari et al. (2016) concludes that challenge could be an especially strong predictor of learning outcomes. Hung et al. (2015) investigated whether challenging games are more able than matching games to improve the students' motivation. They report that students involved in the challenging games achieved better flow experience (Csikszentmihalyi 1990), learning performance, and satisfaction.

Previous research regarding the motivational role of the "genuine active involvement" also revealed that meaningful interactivity could significantly contribute to positive attitude, quality of learning, and motivation (Grigorovici et al. 2003; Sundar et al.2003; Thorson and Rodgers 2006; Evans and Gibbons 2007). For example Lumpkin et al. (2015), report that the participants of their investigation especially valued their active involvement in learning activities highlighting that engagement positively impacted their learning.

Our conclusion with respect to the role of "doing phases" in unmasking false sensations of understanding is in line with the statement Nemirow (1995) made regarding the phenomenon of understanding: "To understand is to be able to implement or apply a rule". According to Wittgenstein (2009), someone who exclaims that "Now I can go on!", but fails to do so, certainly did not understand. Brantingham (2011) argues that the feeling that accompanies understanding (a belief that we have got the idea) should not be equated with the real understanding. If this feeling is not followed by explanation or action, then understanding has not occurred.

\section{Limitations}

A first limitation of this study is that the majority of H-students were females and most S-students were males (as mentioned above this distribution is characteristic to these educational programs). This fact could affect our results. For example, the significant differences we detected between groups regarding the anxiety factor could partly be caused by gender differences. This would be in line with several studies that investigated the effect of gender on computer anxiety. For example, McIlroy et al. (2001) report in persisting gender differences on self-reported computing anxiety. In a similar study (performed in the same country where our investigation was implemented) the authors also detected significant gender effect with respect to computer anxiety (Durndell and Haag 2002).

The only component where H-students' scores were higher than those of their S-colleagues is participants' appreciation regarding their forecasted involvement in following learning-unit (see Fig. 11). But this result could also be perturbed by gender differences. For example, Khan et al. (2017) report that in the game-based learning context they have analyzed girls outperformed boys in terms of engagement. 
Another limitation of our approach is that the learning session we designed included only one algorithm, a specific sorting algorithm. In addition, definitions of CT emphasize that promoting this skill involves more than supporting students in assimilating basic computer algorithms (Shute et al. 2017).

\section{Conclusion and future plans}

We share the conviction of Grover and Pea (2013) that just as basic literacy in mathematics and the sciences are considered essential for understanding how our world works, CT is just as essential in understanding how the all-pervasive computing devices work. Accordingly, a unified "CT for all" approach, akin to initiatives like "Science for all" or "Arts for all", which is carefully designed and properly calibrated, and which bridges the diversity gaps in order to target all learning communities, is a major endeavor. The study we presented should encourage curriculum developers and instructional designers to analyze the possibility of designing and developing unified CT promoter learning environments for all students.

Recently, new dance choreographies were added to the AlgoRythmics (2019) collection which considerable increased its diversity. The website that attaches interactive animations to the videos is under reconstruction. It will also allow registered teachers to create e-learning courses by freely combining learning steps built around the videos and animations. Consequently, the renewed AlgoRythmics environment (including three searching and seven sorting algorithms) will offer great opportunities for practitioners to design and implement learning sessions in the spirit of this study. We are planning to elaborate a one semester syllabus which can be easily adapted to the needs of both humanities- and sciences-oriented students.

Acknowledgements Open access funding provided by Sapientia Hungarian University of Transylvania (EMTE).

\section{Compliance with ethical standards}

Conflict of interest The authors declare that they have no conflict of interest.

Ethical approval This study was approved by the university human research ethics committee and all procedures performed in studies involving human participants were in accordance with the ethical standards of the institutional and/or national research committee and with the 1964 Helsinki declaration and its later amendments or comparable ethical standards.

Informed consent Informed consent was obtained from all individual participants included in the study.

Open Access This article is licensed under a Creative Commons Attribution 4.0 International License, which permits use, sharing, adaptation, distribution and reproduction in any medium or format, as long as you give appropriate credit to the original author(s) and the source, provide a link to the Creative Commons licence, and indicate if changes were made. The images or other third party material in this article are included in the article's Creative Commons licence, unless indicated otherwise in a credit line to the material. If material is not included in the article's Creative Commons licence and your intended use is not permitted by statutory regulation or exceeds the permitted use, you will need to obtain permission directly from the copyright holder. To view a copy of this licence, visit http://creativecommons.org/licenses/by/4.0/. 


\section{Appendix}

\section{Questionnaire 1}

1. I understand the concept of algorithm.

2. I understand what a sorting algorithm means.

3. I am totally unfamiliar with this subject.

4. I agree that algorithmic thinking is a valuable ability that I should posses.

5. I agree that understanding how sorting algorithms work can enhance my algorithmic thinking.

\section{Questionnaire 2}

1. (E) I like the idea behind this e-learning session.

2. (E) I consider that combining arts (folk dances) with sciences (computer algorithms) is an interesting idea.

3. (E) I consider that combining something so modern (computer sciences) with something so traditional (folk dances) is a surprising idea.

4. (E) I am curious about how sorting algorithms work.

5. (E) I am curious about this e-learning session due to the dances.

6. (E) I am curious about this e-learning session because of the art-science combination.

7. I understood in what aspects of the choreography I should focus on:

- to identify the comparing and swapping operations;

- to identify the traverses of the number-sequence;

- to identify the sorting strategy.

8. I understood that this e-learning session implies a substantial active participation from me: to understand, reconstruct and orchestrate the studied sorting algorithm.

9. (C) To identify a danced strategy has to be a non trivial task.

10. (C) I am afraid that what this e-learning session implies is beyond me.

11. (I) The idea of reconstructing and orchestrating an algorithm attracts me.

Questionnaire 3

1. (E) I liked this phase of the e-learning session.

2. (E) I enjoyed the dance-performance.

3. (E) The dance choreography helped me to imagine what a sorting algorithm means.

4. (E) I did not realize what was going on.

5. (E) I caught the logic of the sorting strategy.

6. (C) This e-learning session seems to be a challenging one.

7. (C) I hope the computer animation will help me to understand more deeply the algorithm.

8. (I) The idea that I will have to try to orchestrate such a complex strategy scares me.

9. (I) All my confidence is in the help button.

Questionnaire 4

1. (E) I liked this phase of the e-learning session. 
2. (E) The animation was expressive and interesting.

3. (E) I did not realize what was going on.

4. (E) I realized the correspondences between the dance-choreography and the computer animation (comparing, swapping, traverses ...).

5. (E) I caught the logic of the sorting strategy.

6. I understood what to reconstruct/orchestrate (using the mouse) an algorithm means:

- to choose (according to the strategy of the algorithm)

- the next pair of elements to be processed,

- the proper operation (comparing or swapping) to be applied.

7. I understood what the role of the help button is:

- to inform me about the next step to be performed (what operation on what elements has to be applied).

8. I understood that my performance is measured on:

- how many faults (wrong pair of elements or wrong operation) I have made,

- how many times I have used the help button.

9. (I) I appreciate that the software makes possible to "do" what I have just "heard" and "seen".

10. (C) To reconstruct the same operation-sequence does not seem to be a complicate task.

11. (I) I appreciate that a help button has been implemented to bring me through the possible stuck points.

12. (C) I hope I will not need to use the help button in the reconstructing process.

\section{Questionnaire 5}

1. (E) I liked this phase of the e-learning session.

2. (E) I like the way the software implements the principle of "hearing, seeing, doing".

3. (E) I am positively surprised that I made only a few faults.

4. (E) I often applied guessing.

5. (E) My memory helped me in the reconstruction process.

6. (E) I reached this performance because I understood the strategy the algorithm applies.

7. (E) I am disappointed that I was forced to use the help button so many times.

8. (E) It would be better if I made use of the help button more efficiently.

9. (E) "Doing the algorithm" I better understand it.

10. (I) I appreciate that the software makes possible to choose between repeating the current level task and moving to the next level task.

11. (C) I would like to repeat this task until I manage to perform it faultless.

12. (C) Although I made some mistake it would be boring to try it again.

13. (I) I appreciate that the software makes possible to orchestrate the algorithm on randomly generated input sequences.

14. (C) To orchestrate this strategy on random input sequences will be a challenging task.

15. (C) I consider that what this e-learning session implies is beyond me.

16. (I) I appreciate that a help button has been implemented to bring me through the possible stuck points.

17. (C) I think I will not need to use the help button in orchestrating the algorithm on any input sequence. 
Questionnaire 6

1. (E) I liked this phase of the e-learning session.

2. (E) I like the way the software implements the principle of progressive difficulty.

3. (E) I am positively surprised that I made only a few faults.

4. (E) I often applied guessing.

5. (E) I reached this performance because I understood the strategy the algorithm applies.

6. (E) I am disappointed that I was forced to use the help button so many times.

7. (E) It would be better if I made use of the help button more efficiently.

8. (E) Orchestrating the algorithm I identified lacunas in my understanding of the algorithm.

9. I understood that although the numbers will be hidden, I will be informed about the results of the comparing operations.

10. (I) I appreciate that the software makes possible to choose between repeating the current level task and moving to the next level task.

11. (C) I would like to repeat this task until I manage to perform it faultless.

12. (C) Although I made some mistake it would be boring to try it again.

13. (I) I appreciate that the software makes possible to test the solidity of my understanding regarding the algorithm on hidden sequences.

14. (C) Since I caught the logic of the strategy no problem for me to orchestrate it on hidden sequences.

15. (C) I consider that what this e-learning session implies is beyond me.

16. (I) I appreciate that a help button has been implemented to bring me through the possible stuck points.

17. (C) I hope that I will be able to perform the "black-box orchestration process" without using the help button.

\section{Questionnaire 7}

1. (E) I liked this phase of the e-learning session.

2. (E) I like the way the software implements the principle of progressive difficulty.

3. (E) I am positively surprised that I made only a few faults.

4. (E) I often applied guessing.

5. (E) I reached this performance because I understood the strategy the algorithm applies.

6. (E) I am disappointed that I was forced to use the help button so many times.

7. (E) It would be better if I made use of the help button more efficiently.

8. (E) Orchestrating the algorithm on a hidden sequence revealed further lacunas in my understanding of the algorithm.

9. (I) I appreciate that the software makes possible to choose between repeating the current level task and moving to the next level task.

10. (C) I would like to repeat this task until I manage to perform it faultless.

11. (C) Although I made some mistake it would be boring to try it again.

12. (C) I consider that what this e-learning session implies is beyond me.

13. (E) I am curious to see the parallel illustration of several sorting algorithms on colour scale bars. 
Questionnaire 8

1. (E) I liked this last phase of the e-learning session.

2. (E) The parallel simulation was expressive.

3. (E) The colourful global image the parallel simulation generated was nice.

4. (E) I am curious about the other sorting algorithms, too.

\section{Questionnaire 9}

1. (E) I liked this e-learning session.

2. (E) I liked this e-learning session because of its interestingness.

3. (E) I liked this e-learning session because of its challenge.

4. (E) I liked this e-learning session because of its interactivity.

5. (E) I liked this e-learning session because of the dances.

6. (E) I consider this e-learning experience to be a useful one because it initiated me in what sorting algorithms mean.

7. (E) I consider this e-learning experience to be a useful one because it resulted in a deeper understanding on how the studied algorithm works.

8. (E) I consider this e-learning experience to be a useful one because it may contribute to a developed algorithmic thinking.

9. (E) I would like to study the other sorting algorithms the ending parallel simulation presented.

10. (E) I would recommend this e-learning experience for my friends, too.

\section{References}

Achter, J. A., Lubinski, D., Benbow, C. P., \& Eftekhari-Sanjani, H. (1999). Assessing vocational preferences among gifted adolescents adds incremental validity to abilities: A discriminant analysis of educational outcomes over a 10-year interval. Journal of Educational Psychology, 91(4), 777.

Aho, A. V. (2012). Computation and computational thinking. The Computer Journal, 55(7), 832-835.

AlgoRythmics. (2019). Retrieved May 13, 2019, from https://www.youtube.com/user/AlgoRythmics.

Barger, A., \& Byrd, K. (2011). Motivation and computer-based instructional design. Journal of Cross-Disciplinary Perspectives in Education, 4(1), 1-9.

Baron-Cohen, S. (2003). The essential difference: Men, women and the extreme male brain. London: Penguin.

Berlyne, D. E. (1960). Conflict, arousal, and curiosity. New York: McGraw Hill Book Company Inc.

Billington, J., Baron-Cohen, S., \& Wheelwright, S. (2007). Cognitive style predicts entry into physical sciences and humanities: Questionnaire and performance tests of empathy and systemizing. Learning and individual differences, 17(3), 260-268.

Blumenfeld, P. C. (1992). Classroom learning and motivation: Clarifying and expanding goal theory. Journal of Educational psychology, 84(3), 272.

Blumenfeld, P. C., \& Meece, J. L. (1988). Task factors, teacher behavior, and students' involvement and use of learning strategies in science. The Elementary School Journal, 88(3), 235-250.

Brantingham, A. (2011). Understanding. Macalester Journal of Philosophy, 12(1), 4.

Christophel, D. M. (1990). The relationships among teacher immediacy behaviors, student motivation, and learning. Communication Education, 39, 323-340.

Clark, R. C., \& Mayer, R. E. (2002). e-learning and the science of instruction. San Francisco: Jossey-Bass/ Pfeiffer.

Csikszentmihalyi, M. (1990). Flow: The psychology of optimal experience. New York: Harper Perennial. 
Deci, E. L., \& Ryan, R. M. (1985). Intrinsic motivation and self-determination in human behavior. New York: Plenum.

Denning, P. J. (2009). The profession of IT Beyond computational thinking. Communications of the ACM, 52(6), 28-30.

Denning, P. J. (2017). Remaining trouble spots with computational thinking. Communications of the ACM, 60(6), 33-39.

Durndell, A., \& Haag, Z. (2002). Computer self efficacy, computer anxiety, attitudes towards the Internet and reported experience with the Internet, by gender, in an East European sample. Computers in human behavior, 18(5), 521-535.

Evans, C., \& Gibbons, N. J. (2007). The interactivity effect in multimedia learning. Computers \& Education, 49(4), 1147-1160.

Fair, E. M., \& Silvestri, L. (1992). Effects of rewards, competition and outcome on intrinsic motivation. Journal of Instructional Psychology, 19(1), 3.

Fassbender, E., Richards, D., Bilgin, A., Thompson, W. F., \& Heiden, W. (2012). VirSchool: The effect of background music and immersive display systems on memory for facts learned in an educational virtual environment. Computers \& Education, 58(1), 490-500.

Finneran, C. M., \& Zhang, P. (2005). Flow in computer-mediated environments: Promises and challenges. Communications of the Association for Information Systems, 15(1), 4.

Friedl, R., Höppler, H., Ecard, K., Scholz, W., Hannekum, A., Oechsner, W., et al. (2006). Comparative evaluation of multimedia driven, interactive, and case-based teaching in heart surgery. The Annals of thoracic surgery, 82(5), 1790-1795.

Futschek, G. (2006). Algorithmic thinking: The key for understanding computer science. In International Conference on Informatics in Secondary Schools-Evolution and Perspectives (pp. 159-168). Berlin Heidelberg: Springer.

Garris, R., Ahlers, R., \& Driskell, J. E. (2002). Games, motivation, and learning: A research and practice model. Simulation \& gaming, 33(4), 441-467.

Grigorovici, D., Nam, S., \& Russill, C. (2003). The effects of online syllabus interactivity on students' perception of the course and instructor. The Internet and Higher Education, 6, 41-52.

Grover, S., \& Pea, R. (2013). Computational thinking in K-12: A review of the state of the field. Educational Researcher, 42(1), 38-43.

Guzdial, M. (2008). Education Paving the way for computational thinking. Communications of the ACM, $51(8), 25-27$.

Hamid, A. A. (2001). e-Learning: Is it the "e" or the learning that matters? The Internet and Higher Education, 4(3-4), 311-316.

Hamari, J., Shernoff, D. J., Rowe, E., Coller, B., Asbell-Clarke, J., \& Edwards, T. (2016). Challenging games help students learn: An empirical study on engagement, flow and immersion in game-based learning. Computers in human behavior, 54, 170-179.

Hoffler, T. N., \& Leutner, D. (2007). Instructional animation versus static pictures: A meta-analysis. Learning and Instruction, 17, 722-738.

Hundhausen, C., Douglas, S. A., \& Stasko, J. T. (2002). A meta-study of algorithm visualization effectiveness. Journal of Visual Languages and Computing, 13(3), 259-290.

Hung, C. Y., Sun, J. C. Y., \& Yu, P. T. (2015). The benefits of a challenge: Student motivation and flow experience in tablet-PC-game-based learning. Interactive Learning Environments, 23(2), 172-190.

Jain, A., Duin, R., \& Mao, J. (2000). Statistical pattern recognition: A review. IEEE Transactions on Pattern Analysis and Machine Intelligence, 22, 4-37.

Jain, A. K., \& Duin, R. P. W. (2004). Pattern recognition. In R. L. Gregory (Ed.), The Oxford companion to the mind (2nd ed., pp. 698-703). Oxford, UK: Oxford University Press.

Jonassen, D. H., Peck, K. L., \& Wilson, B. G. (1999). Learning with technology: A constructivist perspective. Upper Saddle River, NJ: Merrill.

Kalyuga, S., Chandler, P., \& Sweller, J. (1999). Managing spilt attention and redundancy in multimedia instruction. Applied Cognitive Psychology, 13, 351-371.

Katai, Z. (2014, June). Selective hiding for improved algorithmic visualization. In Proceedings of the 2014 conference on Innovation \& technology in computer science education (pp. 33-38).

Katai, Z. (2015). The challenge of promoting algorithmic thinking of both sciences-and humanities-oriented learners. Journal of Computer Assisted Learning, 31(4), 287-299.

Keller, J. M. (1983). Motivational design of instruction. Instructional Design Theories and Models: An Overview of Their Current Status, 1(1983), 383-434.

Keller, J. M. (1987). Development and use of the ARCS model of instructional design. Journal of Instructional Development, 10(3), 2. 
Keller, J., \& Suzuki, K. (2004). Learner motivation and e-learning design: A multinationally validated process. Journal of educational Media, 29(3), 229-239.

Khan, A., Ahmad, F. H., \& Malik, M. M. (2017). Use of digital game based learning and gamification in secondary school science: The effect on student engagement, learning and gender difference. Education and Information Technologies, 22(6), 2767-2804.

Lee, O., \& Anderson, C. W. (1993). Task engagement and conceptual change in middle school science classrooms. American educational research journal, 30(3), 585-610.

Lee, O., \& Brophy, J. (1996). Motivational patterns observed in sixth-grade science classrooms. Journal of Research in Science Teaching: The Official Journal of the National Association for Research in Science Teaching, 33(3), 303-318.

Lepper, M. R., \& Malone, T. W. (1987). Intrinsic motivation and instructional effectiveness in computerbased education. Aptitude, learning, and instruction, 3, 255-286.

Lepper, M. R., Corpus, J. H., \& Iyengar, S. S. (2005). Intrinsic and extrinsic motivational orientations in the classroom: Age differences and academic correlates. Journal of Educational Psychology, 97(2), 184.

Litman, J. (2005). Curiosity and the pleasures of learning: Wanting and liking new information. Cognition \& Emotion, 19(6), 793-814.

Lumpkin, A., Achen, R. M., \& Dodd, R. K. (2015). Student perceptions of active learning. College Student Journal, 49(1), 121-133.

Malone, T. W., \& Lepper, M. R. (1987). Making learning fun: A taxonomy of intrinsic motivations for learning. Aptitude, Learning, and Instruction, 3, 223-253.

Martens, R., Gulikers, J., \& Bastiaens, T. (2004). The impact of intrinsic motivation on e-learning in authentic computer tasks. Journal of Computer Assisted Learning, 20(5), 368-376.

Mayer, R. E. (2003). Learning and instruction. Upper Saddle River, NJ: Prentice Hall.

Mayer, R. E., \& Chandler, P. (2001). When learning is just a click away: Does simple interaction foster deeper understanding of multimedia messages? Journal of Educational Psychology, 93, 390-397.

McIlroy, D., Bunting, B., Tierney, K., \& Gordon, M. (2001). The relation of gender and background experience to self-reported computing anxieties and cognitions. Computers in Human Behavior, $17(1), 21-33$.

Meij, J., \& Jong, T. (2006). Supporting students' learning with multiple representations in a dynamic simulation-based learning environment. Learning and Instruction, 16(3), 199-212.

Mork, S. M. (2011). An interactive learning environment designed to increase the possibilities for learning and communicating about radioactivity. Interactive Learning Environments, 19(2), 163-177.

Nakamura, J., \& Csikszentmihalyi, M. (2002). The concept of flow. In C. R. Snyder \& J. L. Shane (Eds.), Handbook of positive psychology (pp. 89-105). New York: Springer.

Nemirow, L. E. (1995). Understanding rules. The Journal of Philosophy, 92(1), 28-43.

Omrod, J. E. (2002). Educational Psychology (4th ed.). Upper Saddle River, NJ: Prentice Hall.

Ott, M., \& Tavella, M. (2010). Motivation and engagement in computer-based learning tasks: Investigating key contributing factors. World Journal on Educational Technology, 2(1), 01-15.

Parrish, P. E. (2009). Aesthetic principles for instructional design. Educational Technology Research and Development, 57(4), 511-528.

Pedró, F. (2006). The New Millennium learners: challenging our views on ICT and learning. OECDCERI. Retrieved May 13, 2019, from https://www.oecd.org.

Rheinberg, F., Vollmeyer, R., \& Burns, D. A. (2001). QCM: A questionnaire to assess current motivation in learning situations. Diagnostica, 47, 57-66.

Riaz, S., Rambli, D. R. A., Salleh, R., \& Mushtaq, A. (2011). Exploratory factor analysis (EFA) to examine learner's aesthetic perceptions and motivation through their aesthetic-emotions in informal visual environments. Information Technology Journal, 10(7), 1268-1284.

Robertson, J., \& Howells, C. (2008). Computer game design: Opportunities for successful learning. Computers \& Education, 50(2), 559-578.

Rovai, A., Ponton, M., Wighting, M., \& Baker, J. (2007). A comparative analysis of student motivation in traditional classroom and elearning courses. International Journal on E-Learning, 6(3), 413-432.

Schrader, C., Brich, J., Frommel, J., Riemer, V., \& Rogers, K. (2017). Rising to the challenge: An emotion-driven approach toward adaptive serious games. In Serious games and edutainment applications (pp. 3-28). Springer, Cham.

Selby, C., \& Woollard, J. (2013). Computational thinking: The developing definition. University of Southampton. Retrieved May 13, 2019, from https://eprints.soton.ac.uk/id/eprint/356481.

Shaffer, C., Cooper, M. L., Alon, A. J. D., Akbar, M., Stewart, M., Ponce, S., et al. (2010). Algorithm visualization: The state of the field. ACM Transactions on Computing Education, 10, 1-22. 
Shute, V. J., Sun, C., \& Asbell-Clarke, J. (2017). Demystifying computational thinking. Educational Research Review, 22, 142-158.

Snow, C. P. (1959). The Two Cultures and the Scientific Revolution. New York: Cambridge University Press.

Sundar, S. S., Kalyanaraman, S., \& Brown, J. (2003). Explicating website interactivity: Impression-formation effects in political campaign sites. Communication Research, 30(1), 30-59.

Tedre, M., \& Denning, P. J. (2016, November). The long quest for computational thinking. In Proceedings of the 16th Koli Calling International Conference on Computing Education Research (pp. 120-129).

Thorson, K. S., \& Rodgers, S. (2006). Relationships between blogs as eWOM and interactivity, perceived interactivity, and parasocial interaction. Journal of Interactive Advertising, 6(2), 5-44.

Triberti, S., Chirico, A., La Rocca, G., \& Riva, G. (2017). Developing emotional design: Emotions as cognitive processes and their role in the design of interactive technologies. Frontiers in Psychology, 8, 1773.

Turner, J. C., \& Meyer, D. K. (2004). A classroom perspective on the principle of moderate challenge in mathematics. The Journal of Educational Research, 97(6), 311-318.

Um, E. R., Song, H., \& Plass, J. (2007, June). The effect of positive emotions on multimedia learning. In EdMedia+ Innovate Learning (pp. 4176-4185). Association for the Advancement of Computing in Education (AACE).

Valle, A., Cabanach, R. G., Rodríguez, S., Nuñez, J. C., González-Pienda, J. A., Solano, P., \& Rosário, P. (2011). A motivational perspective on the self-regulated learning in higher education. Journal of Education Research, 5.

Vollmeyer, R., Burns, B. D., \& Rheinberg, F. (2000). Goal specificity and learning with a multimedia program. In Proceedings of the Annual Meeting of the Cognitive Science Society (Vol. 22, No. 22).

Wang, Q. (2009). Designing a web-based constructivist learning environment. Interactive Learning Environments, $17(1), 1-13$.

Weiner, B. (1990). History of motivational research in education. Journal of educational Psychology, 82(4), 616.

Wing, J. M. (2006). Computational thinking. Communications of the ACM, 49(3), 33-35.

Witkin, H. A., Moore, C. A., Goodenough, D. R., \& Cox, P. W. (1977). Field dependent and field independent cognitive styles and their educational implications. Review of Educational Research, 47, 1-64.

Wittgenstein, L. (2009). Philosophical investigations. New York: Wiley.

Wlodkowski, R. J. (1985). Enhancing adult motivation to learn. San Francisco: Jossey-Bass.

Wu, M. L., \& Richards, K. (2011). Facilitating computational thinking through game design. In M. Chang, W. Y. Hwang, M. P. Chen, \& W. Müller (Eds.), Proceedings of Edutainment Technologies. Educational games and virtual reality/augmented reality applications (pp. 220-227). Berlin, Heidelberg: Springer.

Publisher's Note Springer Nature remains neutral with regard to jurisdictional claims in published maps and institutional affiliations.

Zoltan Katai started his professional career (1992-) as an informatics teacher in secondary education. Nowadays (2001-) he is an associate professor (2014-) at Sapientia Hungarian University of Transylvania (Mathematics and Informatics Department), Targu Mures, Romania. His research includes topics like computer science education, computer assisted instruction, dynamic rogramming, graph algorithms. 